\title{
On the incidence of commissions in auction markets
}

\author{
Victor Ginsburgh $^{\text {a }}$, Patrick Legros ${ }^{b, *}$, Nicolas Sahuguet ${ }^{c}$ \\ a ECARES, Université Libre de Bruxelles and CORE, Université Catholique de Louvain, Belgium \\ b ECARES, Université Libre de Bruxelles and CEPR, Belgium \\ ${ }^{\mathrm{c}}$ HEC Montréal, CEPR and CIRPEE, Canada
}

\section{A R T I C L E I N F O}

\section{Article history:}

Received 22 October 2009

Received in revised form 17 February 2010

Accepted 26 February 2010

Available online 4 March 2010

\section{JEL classifications: \\ L120 \\ L400 \\ D440 \\ Keywords: \\ Auction \\ Intermediation \\ Commissions \\ Welfare}

\section{Introduction}

Intermediation in auctions is the rule rather than the exception: traditional auction houses such as Christie's or Sotheby's are leading examples. Intermediaries obtain revenues by charging commissions on buyers and sellers that eventually affect the final trading price. Understanding the performance of such markets, for instance whether buyers end up facing too high prices because of collusion between intermediaries or abuse of market power by some of them, requires an analysis of the welfare consequences of commissions. ${ }^{1}$

These consequences seem easy to assess. After all commissions are ad-valorem taxes and we could simply refer to well known results on the tax incidence of ad-valorem taxes in competitive markets. Three important observations are made in this literature. ${ }^{2}$

\footnotetext{
* Corresponding author.

E-mail address: plegros@ulb.ac.be (P. Legros).

${ }^{1}$ There have been recent concerns about the ability of intermediaries to charge too large commissions. The price fixing agreement between Christie's and Sotheby's from 1993 to 2000, illustrates the possibility of collusion in commission rates between intermediaries (see (Ashenfelter and Graddy, 2005)). Similarly, the European and U.S. antitrust authorities have expressed worries about the market power of B2B platforms and their ability to charge excessive prices or to deter entry in the market for intermediation; see for instance the remarks made by the FTC Commissioner (Swindle, 2000), or the survey by (Wiseman, 2000).

${ }^{2}$ See for instance the survey by (Fullerton and Metcalf, 2002).
}

1. In standard markets, the incidence of ad-valorem taxes is identical whether it is the buyer or the seller who is imposed, as long as it creates the same wedge between the prices paid by the buyer and those received by the seller.

2. Higher taxes make both buyers and sellers weakly worse off. ${ }^{3}$

3. The direction of the welfare change is the same whether agents buy or refrain from doing so.

Economists tend to assume that the same rules of tax incidence that apply to competitive markets apply to other forms of market organization. This may not be so, since the traditional analysis of such incidence is based on the following two assumptions that are likely to be violated in auction markets:

- First, the participation of buyers and sellers is exogenous; it does not depend on the price. This implies in particular that the shift in aggregate demand (or supply) reflects only the level of the tax, the number of sellers and buyers being constant.

- Second, the demand and supply schedules are assumed to be independent. For instance, a tax on consumers induces a shift of the demand schedule only.

\footnotetext{
${ }^{3}$ Moreover, the relative losses of buyers and sellers are a function of demand and supply elasticities. For instance, if supply is inelastic, buyers are not hurt by an increase in taxes; sellers will bear the full burden. If supply is elastic, both buyers and sellers will be worse off.
} 
The two traditional assumptions seem reasonable. For instance, in Walrasian markets, properly taking into account participation of consumers would just lead to a more elastic realized demand in the market. This would not reverse the qualitative consequences (1)-(3) but their magnitudes. However these assumptions are not innocuous in auction markets, where, as we will show, even the welfare effects may be qualitatively different when participation is accounted for.

In auctions, a raise in commissions implies a shading of the bid functions but should not affect the welfare of buyers since their probability of winning and the price they pay is the same. Hence $a$ priori there should be no change in the number of buyers willing to participate in the auction. However, this shading of the bid decreases the price, thus affecting the seller who can react by strategically changing his reserve price. To the extent that the reserve price affects the outcome of the auction, buyers can be indirectly hurt. It follows that a higher commission induces lower buyers' participation in the auction when sellers set reserve prices strategically. Thus, a change in commissions affects both supply and demand.

We study these intuitions in a simple auction model with an intermediary. In general, changing the individual levels of buyer and seller commission rates matters for the outcome, even if the total rate is constant. We show that we can define a commission index that is a nonlinear function of the buyer and seller commission rates such that the outcome is invariant to the structure of the rates as long as this commission index remains constant. ${ }^{4}$ The participation of buyers, the seller's reserve price and the equilibrium price depend only on this index.

We then show that, contrary to 2 . and 3 . buyers may be better off. Indeed, the winner of an auction may gain from the lower price if there are fewer buyers and if the second highest price is larger than the reserve price. Hence when the commission index increases, winners in the high-index auction who pay a price strictly larger than the reserve price are strictly better off than if they had been winners in the low-index auction. This result is quite general and does not depend on particular choices of the distribution of valuations.

Our paper connects with the literatures on two-sided markets and on auctions with participation costs. ${ }^{5}$

An intermediary in an auction market could be considered as a 'platform.' (Rochet and Tirole, 2006) propose a definition of two-sided markets based on whether the final price depends on the structure of taxes or only on their sum. An auction market with exogenous participation will therefore be considered one-sided since, as we have already argued, the price received by the seller is independent of whether it is the buyer or the seller who pays the tax or the commission. By contrast, we show that when participation is endogenous, the final price depends in a non-linear fashion on the taxes imposed on buyers and sellers; hence with endogenous participation the auction market is two-sided. Beyond semantics, the two-sided nature of auction markets has important consequences for competition policy since the welfare effects of taxes could be very different from those in one-sided markets.

The fact that the positive and normative analyses in two-sided markets should be different from those in one-sided markets is well understood by researchers (see for instance (Baye and Morgan, 2001), (Caillaud and Jullien, 2001), (Ellison and Fudenberg, 2003), (Wright, 2004)). However, as far as we know, our paper is the first to point out the difference in tax incidence with and without endogenous participation in auction markets and to provide the conditions under which buyers can be strictly better off with higher commissions.

Most of the auction literature deals with a fixed number of buyers. There are some notable exceptions such as the early paper on entry by

\footnotetext{
${ }^{4}$ Note that this is also the case in the standard supply-demand model. See footnotes 13 and 14 .

${ }^{5}$ See (Klemperer, 2003) for a discussion of the importance of participation costs in auction theory.
}

(Levin and Smith, 1994). ${ }^{6}$ In their model, buyers have identical participation costs and entry strategies are mixed and symmetric. The probability of entry is set such that the expected surplus of a buyer is exactly equal to his participation cost. Since we want to compare the welfare of participants, we introduce heterogeneity in participation costs. Hence, participating buyers will in general have a positive surplus.

The classic treatment of reserve prices in auctions is (Myerson, 1981). ${ }^{7}$ He derives his results with a fixed number of buyers. We extend the analysis to the case in which buyers and seller have to pay commissions. In our analysis, the seller rationally responds to an increase in the commission index with an increase in the reserve price since the opportunity cost of not selling the object has now decreased. This lowers the expected payoff of buyers and leads to a decrease in their participation.

We describe the model and the equilibrium in the next section and develop the consequences on the welfare of buyers and sellers in Section 3. We conclude in Section 4.

\section{An auction market with an intermediary}

\subsection{The model}

A typical auction consists of one seller with valuation $v_{s}$ and $N$ potential buyers, each with a participation cost $t$, where $t$ is a random variable with distribution $G(t){ }^{8}$ The buyers who choose to participate in the auction are called 'bidders'; their number is endogenous and is denoted by $n, n \leq N$. Each buyer wants to purchase one unit only of the good and can participate in one auction only. Bidders' valuations $v$ are distributed according to $F(v)$.

There is a unique intermediary who sets commission rates $\left(c_{B}, c_{S}\right)$, on buyers and sellers respectively. ${ }^{9}$

The auction format is the second price (Vickrey) auction; this form is strategically equivalent to the English auction used by traditional auction houses. ${ }^{10}$ The timing is the following: at $t=1$, buyers choose whether to participate or not in the auction; at this stage, they do not yet know their valuations; at $t=2$, the seller sets a reserve price $r ;{ }^{11}$ finally, at $t=3$, each bidder observes his valuation and makes his bid. ${ }^{12}$

\subsection{Equilibrium}

We now derive the expressions for the hammer price $p$, the profit of the seller, $\Pi($.$) , his optimal reserve price r$, and the surplus of buyers, $B^{A}($.), and show that their surplus depends only on $r$ and $n$. It is independent of commissions insofar as the effect of commissions on $r$ and $n$ is taken into account. Similarly the price expected by the seller is

\footnotetext{
${ }^{6}$ See also chapter 6 of (Milgrom, 2004) for a treatment of auctions with entry

7 See also (Engelbrecht-Wiggans, 1987) and (Burguet and Sákovics, 1999) for additional references.

${ }^{8}$ We assume that sellers bear no participation cost since this would not change our main results. In particular, the key observation that the expected number of buyers per auction decreases with the commission index would obtain in a model with many sellers and a participation cost.

${ }^{9}$ The reader may want to have in mind intermediaries such as Christie's setting commissions, which would be the natural interpretation in our case, but the analysis could also apply to a state setting tax rates on transaction prices.

${ }^{10}$ Since the revenue equivalence principle can be applied in our framework, our results would not change if we used any other usual auction format.

${ }^{11}$ The fact that the reserve price is often secret, coincides with reality, but does not matter here.

${ }^{12}$ Assuming that buyers learn their valuation after having decided to participate is for technical convenience: otherwise, participation signals valuations. Such a situation is reasonable when the characteristics of the good that is auctioned are fully discovered only after participation, like the quality of flowers in a tulip market, the 'actual' painting rather than the picture in the sales catalogue, etc. It is the usua assumption in the literature on auctions with entry, as in (Levin and Smith, 1994) for instance, though there also exist papers with endogenous participation in which bidders know their valuations prior to the entry decision, as in (Menezes and Monteiro, 2000).
} 
independent of commissions: it is obtained by simply multiplying a commission-independent price by the non-linear commission index defined as

$\alpha=\frac{c_{B}+c_{S}}{1+c_{B}}$,

where $c_{S}$ and $c_{B}$ represent the commission rates levied on the seller and on buyers. ${ }^{13}$

Let $b_{(1)}$ and $b_{(2)}$ be the highest and second highest bids among the $n$ bids. With a reserve price $r$, the object is sold to the highest bidder only if $b_{(1)} \geq r$ at a hammer price equal to the maximum between $r$ and $b_{(2)}$. Let $F_{(1, n)}$ be the distribution of the first order statistic when there are $n$ buyers and let $F_{(2, n)}(x \mid y)$ be the distribution of the second order statistic when the first order statistic is equal to $y$.

The dominant strategy of a bidder with valuation $v$ is to bid $b=v /\left(1+c_{B}\right)$. Hence, if there are $n$ bidders, the $i$-th order bid is $b_{(i)}=v_{(i)} /\left(1+c_{B}\right)$, where $v_{(i)}$ is the $\mathrm{i}$-th order valuation among the $n$ bidders.

\subsubsection{The hammer price}

The expected hammer price is then

$$
\begin{aligned}
p & =\int_{r\left(1+c_{B}\right)}^{1} \int_{0}^{x} \max \left\{r, \frac{v}{1+c_{B}}\right\} d F_{(2, n)}(v \mid x) d F_{(1, n)}(x) \\
& =\int_{r\left(1+c_{B}\right)}^{1}\left(\int_{0}^{r\left(1+c_{B}\right)} r d F_{(2, n)}(v \mid x)+\int_{r\left(1+c_{B}\right)}^{x} \frac{v}{1+c_{B}} d F_{(2, n)}(v \mid x)\right) d F_{(1, n)}(x) .
\end{aligned}
$$

\section{Setting}

$\rho \equiv r\left(1+c_{B}\right)$,

we can write the hammer price as,

$p=\frac{1}{1+c_{B}} I(\rho, n)$

where

$I(\rho, n) \equiv \int_{\rho}^{1}\left(\int_{0}^{\rho} \rho d F_{(2, n)}(v \mid x)+\int_{\rho}^{x} v d F_{(2, n)}(v \mid x)\right) d F_{(1, n)}(x)$.

$I(\rho, n)$ corresponds to the hammer price in an auction with no commission when the reserve price is $\rho$.

\subsubsection{The seller's profit and reservation price}

The expected profit of the seller is now

$$
\begin{aligned}
\Pi(\alpha, \rho, n) & =\frac{1-c_{S}}{1+c_{B}} I(\rho, n)+F^{n}(\rho) v_{s} \\
& =(1-\alpha) I(\rho, n)+F^{n}(\rho) v_{s}
\end{aligned}
$$

and a strategic seller chooses $\rho$ to maximize $\Pi .{ }^{14}$ Note that $\Pi$ is a function of the nonlinear commission index $\alpha$.

\footnotetext{
${ }^{13}$ In the usual D-S model, with ad valorem taxes $c_{B}$ and $c_{S}$ on buyers and sellers, buyers will pay a net price $p\left(1+c_{B}\right)$ and sellers receive a net price $p\left(1-c_{S}\right)$ where $p$ is the price before taxes. Therefore, a tax policy that leaves the tax index $\beta=\left(1-c_{S}\right) /$ $\left(1+c_{B}\right)$ unchanged will lead to the same equilibrium price as without taxes. Note that $\alpha=1-\beta$.

${ }^{14}$ We assume that the seller chooses an optimal reserve price, but our qualitative results would still obtain if we simply assumed that $\rho$ is increasing in $\alpha$. That would be so if the seller sets $\rho=v_{s} /\left(1-c_{s}\right)$ in order to guarantee a price net of commission larger than his valuation $v_{s}$.
}

As we show in Appendix A, the optimal reserve price $r$ is independent of the number of bidders and solves the equation: ${ }^{15}$

$r-\frac{1-F(r)}{f(r)}=\frac{v_{s}}{1-\alpha}$.

\subsubsection{The buyer's surplus}

Standard arguments imply that the marginal surplus of a bidder is the expected probability of winning. If the reserve price is $r$ (a function of $\alpha$ ), all bidders with valuation $v<\rho=r\left(1+c_{B}\right)$ have a zero probability of winning. Hence, the expected surplus of a bidder with valuation $v \geq \rho$ is

$B^{I}(v, \alpha, \rho, n)=\int_{\rho}^{v} F^{n-1}(x) d x$.

Ex-ante (before knowing his valuation), the surplus of a buyer in an auction with $n$ participants is then

$B^{A}(\alpha, \rho, n)=\int_{\rho}^{1} B^{I}(v, \alpha, \rho, n) f(v) d v$

This surplus is clearly decreasing in $n$ (for fixed $\rho$ ) and decreasing in $\rho$ (for fixed $n$ ).

Since commissions decrease revenue, the seller is likely to change his behavior; in particular, he may decide not to participate or to participate but modify his optimal reserve price. This has a feed-back effect on the surplus of buyers and hence on their own participation. Therefore, a change in commissions will change the number of participants in the auction.

A buyer takes $c=\left(c_{S}, c_{B}\right)$ as given and anticipates the reserve price and the participation decision of other buyers. He participates if his cost of participating, $t$, is smaller than his expected surplus.

Proposition 1. There exists a unique equilibrium with positive participation.

Proof. There always exists an equilibrium in which no buyer participates. If there is positive participation, it is characterized by a threshold participation cost $t$ that corresponds to the expected surplus of a buyer who believes that other buyers participate with probability $q$ where $q$ corresponds to the probability that their participation cost is below the threshold $t$. The number of buyers in the auction then follows a binomial distribution with mean $N q$; hence for a given value of $\alpha$, the equilibrium $q$ solves the following two equations:

$t=\sum_{n=1}^{N-1}\left(\begin{array}{c}N-1 \\ n\end{array}\right) q^{n}(1-q)^{N-1-n} B^{A}(\alpha, \rho, n)$

$G(t)=q$

or equivalently,

$G^{-1}(q)=\sum_{n=1}^{N-1}\left(\begin{array}{c}N-1 \\ n\end{array}\right) q^{n}(1-q)^{N-1-n} B^{A}(\alpha, \rho, n)$.

As $n$ increases, $B^{A}(\alpha, \rho, n)$ decreases. Since as $q$ increases, the binomial distribution shifts in the first order stochastic sense, the right hand side decreases with $q$. But since the left hand side is increasing in $q$, there can exist at most one solution with positive participation. $\square$

\footnotetext{
${ }^{15}$ Note that when deriving the optimal reserve price, the seller does not take into account the effect of the reserve price on buyers' participation. This can be interpreted as the seller having no commitment power and that he sets the optimal reserve price once the buyers have decided whether to participate or not. This would also be the case in a market with many sellers in which buyers learn which object they are interested in at the same time as they learn their valuation. The reserve price of a particular seller would thus have no impact on the number of buyers coming to the auction.
} 
The degree of competition of an auction is thus characterized by $q(\alpha)$ and $n^{*}$ the expected number of bidders at the auction.

The outcome of the auction is affected by commissions only to the extent that $\alpha$ is changed. The seller's optimal reserve price is equal to $r=\rho /\left(1+c_{B}\right)$ and thus depends on the commission structure, but since bidders shade their bids by the same factor $\left(b=v /\left(1+c_{B}\right)\right)$, the marginal type of bidder who is excluded from the auction has a valuation $v=\rho$, which depends on $\alpha$ only.

For buyers, Eq. (4) shows that the surplus for a given number $n$ of buyers is equal to

$$
\int_{\rho}^{1} \int_{\rho}^{v} F^{n-1}(x) d x f(v) d v
$$

which depends on $\rho$, and thus on $\alpha$ only. Since participation decisions depend directly on the surplus, the expected number of bidders $n^{*}$ also depends only on $\alpha$.

Proposition 2. Commission rates $\left(c_{S}, c_{B}\right)$ that keep $\alpha=\left(c_{S}+c_{B}\right) /(1+$ $C_{B}$ ) constant generate identical buyers' participation, and identical surpluses and profits for all agents in the model (buyers, seller and intermediary).

\section{Welfare}

The result of Proposition 2 allows us to restrict attention to the analysis of an increase in the commission index from $\alpha$ to $\hat{\alpha}$; the reserve types are $\rho$ and $\hat{\rho}$, and the expected number of bidders are $n^{*}$ and $\hat{n}^{*}$.

The welfare considerations depend mainly on the number of bidders, that is, on how competitive the auction market is. This number determines their probability of winning, and the expected price if they win. To assess the welfare changes of participants, it is therefore necessary to take into account the joint variation of these two variables. This suggests that the welfare consequences of a change in commissions are different when assessed ex-ante (before the bidders get information about their valuation) and ex-post (after the winner is known).

\subsection{Ex ante and interim welfare}

A first result is similar to the standard welfare effect of taxation in standard markets: at the ex-ante stage (before the buyers know their valuations), the seller and buyers are necessarily worse off when the commission index increases.

Proposition 3. Suppose that $v_{s}>0$ and that the seller sets his reserve price strategically. If $\hat{\alpha}>\alpha$, then the expected number of bidders decrease and the ex-ante welfare of buyers and of the seller decrease.

Proof. Suppose by way of contradiction that

$$
\begin{aligned}
& \sum_{n=1}^{N-1}\left(\begin{array}{c}
N-1 \\
n
\end{array}\right) q(\alpha)^{n}(1-q(\alpha))^{N-1-n} B^{A}(\alpha, \rho, n)> \\
& \sum_{n=1}^{N-1}\left(\begin{array}{c}
N-1 \\
n
\end{array}\right) q(\hat{\alpha})^{n}(1-q(\hat{\alpha}))^{N-1-n} B^{A}(\hat{\alpha}, \hat{\rho}, n) .
\end{aligned}
$$

This would lead to a higher threshold of participation and a higher $q(\alpha)$. We also know that $B^{A}(\hat{\alpha}, \hat{\rho}, n) \leq B^{A}(\alpha, \rho, n)$ for all $n$, which leads to an immediate contradiction. In words, higher commissions lead to lower surplus for a given number of bidders. Since participation depends on the ex-ante welfare of buyers, the ex-ante welfare must decrease. Otherwise, with higher ex-ante welfare, we would have two effects reducing surplus (the direct effect of commission and the increase in competition) leading to an increase in surplus, a contradiction.

The elasticity of participation of buyers is one of the important factors that explains the impact of an increase in the commission index. If buyers' participation is very elastic (this is the case when all buyers have the same positive cost of participation), the buyers' exante surplus is left unchanged by the increase in the index. The participation decision decreases competition in the market to the point that it compensates exactly the direct decrease in welfare due to higher index and reserve prices.

While the decision to participate is made at the time they incur the participation cost, after attending the auction some buyers will learn that their valuation is lower than the anticipated reserve price of the seller. At this stage, these buyers could bid but will never win. We call effective bidders the other buyers, those whose valuation is greater than the reservation price.

Clearly, buyers who decided to participate in the auction (paid the participation cost) but are not effective bidders at the interim stage, are worse off when the commission index increases because the reservation price is increasing in $\alpha$ by Eq. (3), implying that for lower values of $\alpha$ they could have been effective bidders.

However, as we show below, effective bidders could strictly gain when the index increases, which is in sharp contrast with standard tax incidence results. Note that Proposition 3 implies that whatever gain the effective bidders obtain when $a$ increases it will be inferior to the loss of all the other buyers.

Proposition 4. Suppose that all buyers have the same cost of participation. Then effective bidders are ex-ante better off in the market with high commissions.

Proof. The ex-ante welfare of effective bidders in the auction with commissions $\hat{\alpha}$, where $\hat{\alpha}>\alpha$ can be written as:

$\int_{\hat{\rho}}^{1} \sum_{n=1}^{N-1}\left(\begin{array}{c}N-1 \\ n\end{array}\right) q(\hat{\alpha})^{n}(1-q(\hat{\alpha}))^{N-1-n} \int_{\hat{\rho}}^{x} F(x)^{n-1} d x f(v) d v$.

The assumption that all buyers have the same cost of participation leads to the ex-ante welfare being independent of the commission $\alpha$. The probability of participation $q(\alpha)$ would adjust so that the ex-ante welfare is equal to the common cost of participation $t$.

Since $\rho<\hat{\rho}$ we thus get:

$$
\begin{aligned}
& \int_{\hat{\rho}}^{1} \sum_{n=1}^{N-1}\left(\begin{array}{c}
N-1 \\
n
\end{array}\right) q(\alpha)^{n}(1-q(\alpha))^{N-1-n} \int_{\hat{\rho}}^{x} F(x)^{n-1} d x f(v) d v \\
& <\int_{\rho}^{1} \sum_{n=1}^{N-1}\left(\begin{array}{c}
N-1 \\
n
\end{array}\right) q(\alpha)^{n}(1-q(\alpha))^{N-1-n} \int_{\hat{\rho}}^{x} F(x)^{n-1} d x f(v) d v \\
& =\int_{\hat{\rho}}^{1} \sum_{n=1}^{N-1}\left(\begin{array}{c}
N-1 \\
n
\end{array}\right) q(\hat{\alpha})^{n}(1-q(\hat{\alpha}))^{N-1-n} \int_{\hat{\rho}}^{x} F(x)^{n-1} d x f(v) d v .
\end{aligned}
$$

Therefore all effective bidders are better off on average in the auction with high commissions than in the auction with low commissions

Note that as long as participation is elastic, that is if the number of buyers participating in the auction strongly reacts to a change of exante welfare, implying thus that the ex-ante welfare in the auction with low commissions is not much smaller than the one in the auction with high commissions, the argument used in the proof of the proposition would still hold by continuity.

The change of average ex-post welfare of winners is usually what economists have in mind when they analyze the effect of an increase in commissions in order to compensate losers. If, ex-ante, buyers are worse-off, it is not clear whether this will also be the case ex-post. 
Since the seller changes the reserve type and since higher reserve types decrease ex-ante welfare of buyers and thus their participation, ex-post, bidders may face less competition (a lower $n$ ). The winner ends up paying less than he would have otherwise. We elaborate on this point in the next section.

\subsection{Ex-post welfare}

The winner of an auction with $n$ participants who has a valuation $v \geq \rho$ has on average a surplus of

$$
B^{P}(v, \rho, n)=\int_{\rho}^{v}\left(v-\max \left(\rho, v_{(2)}\right)\right) d F_{(2, n)}\left(v_{(2)} \mid v ; n\right) .
$$

He pays the second highest bid if it is larger than the reserve price, or pays the reserve price if there is no other larger bid. Indeed, if $v_{(2)} \geq \rho$ the hammer price is $v_{(2)} /\left(1+c_{B}\right)$; otherwise, the hammer price is $r$.

When $v \geq \rho$, we can rewrite $B^{P}(v, \rho, n)$ as

$$
\begin{aligned}
& \int_{0}^{\rho}(v-\rho)(n-1) f(x) \frac{F(x)^{n-2}}{F(v)^{n-1}} d x+\int_{\rho}^{v}(v-x)(n-1) f(x) \frac{F(x)^{n-2}}{F(v)^{n-1}} d x \\
& =(v-\rho)\left(\frac{F\left(r\left(1+c_{B}\right)\right)}{F(v)}\right)^{n-1}+\int_{\rho}^{v}(v-x)(n-1) f(x) \frac{F(x)^{n-2}}{F(v)^{n-1}} d x \\
& =v-\rho\left(\frac{F(\rho)}{F(v)}\right)^{n-1}-\int_{\rho}^{v}(n-1) x f(x) \frac{F(x)^{n-2}}{F(v)^{n-1}} d x .
\end{aligned}
$$

We want to compare the welfare of the winner in the reference auction (with high commissions) to his welfare in the alternative scenario in which commissions were lower.

The parameters of interest are $v$, the valuation of the winner that remains the same in both scenarios, $r$ the reserve price in the reference auction (high commission) and $\hat{r}$ the reserve price in the alternative (low commission) auction $(\hat{r} \leq r, p$ the price paid in the reference auction, $t^{*}$ and $\hat{t}^{*}$ the threshold costs for participation (with $t^{*}<\hat{t}^{*}$ ). With the threshold cost of participation one can associate a probability $q(\alpha)$ of participation and an expected number of bidders in the auction, respectively $n^{*}$ and $\hat{n}^{*}$. We also denote by $n$ the number of observed buyers in the reference auction and $\hat{n}$ the number of buyers that would have participated in the low commission auction.

We observe the result of the reference auction and we need to infer what would have happened in the alternative scenario. We will assume that the participation costs of all $N$ potential buyers remain the same in both scenarios. From the participation decisions in the reference auction, we know that for the $n$ buyers who participated in the auction $t_{i} \leq t^{*}$ and that for the $N-n$ other buyers we had $t_{k} \geq t^{*}$. Since $t^{*}<\hat{t}^{*}$, the bidders in the high commission auction would also have participated in the low commission auction, and some additional bidders could have participated, those with participation cost $t^{*} \leq t_{i} \leq \hat{t}^{*}$. Let us denote by $\hat{\mathrm{v}}$ the highest valuation of those new bidders. Note that on average there would be $\left(n^{*}-\hat{n}^{*}\right)$ additional bidders in the low commission auctions.

We now need to consider two cases:

Case: $p>r$

The welfare of the winner in the reference auction would decrease in the auction with lower commission. To see that, note that additional bidders can change the result of the auction in two ways. When $\hat{v}>v$, the winner would not have won the auction since one of the additional bidders would have bidden more. When $p \leq \hat{v} \leq v$, the winner would still have won the auction but the presence of additional bidders would lead to a higher price. Under both these scenarios, the winner's welfare would be smaller in the case with lower commissions.

Hence, whenever the winner of an auction does not pay the reserve price, he is better off than in an auction with lower commissions and higher participation.

Case: $p=r$

The welfare of the winner in the alternative, low commission, auction could increase because the reservation price of the seller will decrease and it is possible that no new bidder has a valuation $\hat{v}>r$. In this case, the winner pays $\max (\hat{r}, \hat{v})$ instead of $r$, the price he would have paid in the original, high commission, auction.

We summarize the argument in the following proposition:

Proposition 5. If the expected number of bidders decreases with an increase in commission $\left(n^{*}<n^{*}\right)$, and if the observed winner of the auction does not pay the reserve price, then his welfare would be lower in the auction with lower commission but more participation.

The effects of increased commissions for our various welfare measures are displayed the following table.

\begin{tabular}{llll}
\hline Seller & Buyers (ex ante) & $\begin{array}{l}\text { Effective bidders } \\
\text { (interim } v>\hat{p} \text { ) } \\
\text { Worse off }\end{array}$ & Weakly worse off \\
& & $\begin{array}{l}\text { Better off if participation } \\
\text { is elastic }\end{array}$ & $\begin{array}{l}\text { Better off if reserve } \\
\text { price not binding }\end{array}$ \\
\hline
\end{tabular}

\section{Conclusion}

The welfare analysis of commissions is well understood in traditional markets and leads to the simple conclusion that buyers and sellers are worse off. In this paper, we argue that a different analysis is needed in auction markets with intermediaries when participation is endogenous and sellers choose their reserve prices.

A key element of auction markets is that the goods that are exchanged are lotteries; as we show this implies that ex-ante and expost welfare are not necessarily identical. Generally the difference hinges on the observation that buyers who participate in the auction (bidders) can be better off when facing higher commissions: they are compensated for the higher commission by a lower participation of fellow buyers. While rather intuitive, this observation calls for a specific analysis of the welfare effects of non-competitive pricing and of collusion between intermediaries.

The analysis has been cast in a single auction house framework. The extension to competing auction houses is of interest but beyond the scope of this paper. Our conjecture is that our insights should be robust in that environment. In particular, if collusion between auction houses leads to a higher commission index than without collusion, then some winners are better off: indeed, it must be the case that in some auction house the number of buyers is lower than it was before, hence that the conditions of Proposition 5 hold.

The Christie's-Sotheby's collusion case is of particular relevance (see (Ashenfelter et al., 2003) and (Ashenfelter and Graddy, 2005)). The two auction houses were found guilty of colluding between 1993 and 2000. In 2001, a class-action suit ended by each auction house agreeing to pay 256 million dollars to the plaintiffs. Buyers and sellers who had bought or sold through either auction houses between 1993 (1995 for sellers) and 2000 in the United States were compensated. Buyers received the largest share in the settlement. With this decision, compensated bidders may have won twice. First because hammer prices may have been lower than without collusion, and secondly, because they were unrighteously compensated, while sellers may not have been properly compensated. The settlement was obviously based on incomplete understanding of how auctions work. 


\section{Acknowledgment}

We thank the referee for useful comments.

\section{Appendix A.}

\section{A.1. Optimal reserve prices}

The expected payment of a bidder with valuation $v \geq r$ can be written:

$p(v, r)=r F^{n-1}(r)+\int_{r}^{x} y(n-1) f(y) F^{n-2}(y) d y$.

The ex-ante expected payment of a bidder is:

$$
\begin{aligned}
E[p(x, r)] & =\int_{r}^{1} p(v, r) f(x) d x \\
& =\int_{r}^{1}\left(r F^{n-1}(r)+\int_{r}^{x} y(n-1) f(y) F^{n-2}(y) d y\right) f(x) d x \\
& =r(1-F(r)) F^{n-1}(r)+\int_{r}^{1} y(1-F(y))(n-1) f(y) F^{n-2}(y) d y .
\end{aligned}
$$

The expected revenue of the seller is thus $\Pi=(1-\alpha) n E[p(x, r)]+$ $F^{n}(r) v_{s}$. Differentiating with respect to $r$, we obtain:

$$
\begin{aligned}
\frac{\partial \Pi}{\partial r} & =(1-\alpha) n(1-F(r)-r f(r)) F^{n-1}(r)+n F^{n-1}(r) f(r) v_{s} \\
& =(1-\alpha) n\left(1-\left(r-\frac{v_{s}}{1-\alpha}\right) h(r)\right)(1-F(r)) F^{n-1}(r),
\end{aligned}
$$

where $h(x)=f(x) /(1-F(x))$ is the hazard rate associated with distribution $F$.

Since $\partial \Pi / \partial r>0$ at $r=v_{s}$, it is always optimal to choose a reserve price larger than the seller's valuation.
The optimal reserve price has to satisfy $\partial \Pi / \partial r=0$. This will be true if

$1-\left(r-\frac{v_{s}}{1-\alpha}\right) h(r)=0$,

so that

$r-\frac{1-F(r)}{f(r)}=\frac{v_{s}}{1-\alpha}$

\section{References}

Ashenfelter, O., Ginsburgh, V., Graddy, K., Legros, P., Sahuguet, N., 2003. Auction house settlements - winning twice? The Art Newspaper 141.

Ashenfelter, O., Graddy, K., 2005. Anatomy of the rise and fall of a price-fixing conspiracy: auctions at Sotheby's and Christie's. Journal of Competition Law and Economics 1 (1), 3-20.

Baye, M.R., Morgan, J., 2001. Information gatekeepers on the internet and the competitiveness of homogenous markets. The American Economic Review 91 (3), 454-474.

Burguet, R., Sákovics, J., 1999. Imperfect competition in auction designs. International Economic Review 40 (1), 231-247.

Caillaud, B., Jullien, B., 2001. Competing cybermediaries. European Economic Review 45 (4-6), 797-808.

Ellison, G., Fudenberg, D., 2003. Knife-edge or plateau: when do market models tip? Quarterly Journal of Economics 118 (4), 1249-1278.

Engelbrecht-Wiggans, R., 1987. On optimal reservation prices in auctions. Management Science 33 (6), 763-770.

Fullerton, D., Metcalf, G., 2002. Tax incidence. In: Auerbach, A., Feldstein, M. (Eds.), Handbook of Public Economics. Elsevier, Amsterdam, pp. 1787-1872.

Klemperer, P., 2003. Using and abusing economic theory - lessons from auction design. Journal of the European Economic Association 1, 272-300.

Levin, D., Smith, J., 1994. Equilibrium in auctions with entry. The American Economic Review 84 (3), 585-599.

Menezes, F.M., Monteiro, P.K., 2000. Auctions with endogenous participation. Review of Economic Design 5, 71-89.

Milgrom, P., 2004. Putting Auction Theory to Work. Cambridge University Press.

Myerson, R., 1981. Optimal auction design. Mathematics of Operation Research 6 (1), 58-73.

Rochet, J.-C., Tirole, J., 2006. Two-sided markets: a progress report. Rand Journal of Economics 37 (3), 645-667.

Swindle, 0., 2000. Antitrust in the emerging b2b marketplace. http://www.ftc.gov / speeches/swindle/princetonclub2k.shtm.

Wiseman, A.E., 2000. Economic Perspectives on the Internet. FTC report.

Wright, J., 2004. One-sided logic in two-sided markets. Review of Network Economics 3. 42-63. 